\title{
Article \\ On the Sequence of Unmasked Reflections in Shoebox Concert Halls
}

\author{
Juan Óscar García Gómez ${ }^{1, *}$, Oliver Wright ${ }^{2}$, Elisabeth van den Braak ${ }^{3}$, Javier Sanz ${ }^{2}$ (D) Liam Kemp ${ }^{1}$ \\ and Thomas Hulland ${ }^{3}$ \\ 1 Marshall Day Acoustics, Collingwood 3066, Australia; 1kemp@marshallday.com \\ 2 Marshall Day Acoustics, Auckland 1010, New Zealand; oliver.wright@marshallday.co.nz (O.W.); \\ javier.sanz@marshallday.co.nz (J.S.) \\ 3 Marshall Day Acoustics, Wellington 6011, New Zealand; bertie.vandenbraak@marshallday.co.nz (E.v.d.B.); \\ tom.hulland@marshallday.co.nz (T.H.) \\ * Correspondence: jogarciagomez@marshallday.com
}

check for updates

Citation: Gómez, J.Ó.G.; Wright, O.; van den Braak, E.; Sanz, J.; Kemp, L.; Hulland, T. On the Sequence of Unmasked Reflections in Shoebox Concert Halls. Appl. Sci. 2021, 11, 7798. https://doi.org/10.3390/ app11177798

Academic Editors: Nikolaos M. Papadakis, Massimo Garai and Stavroulakis Georgios

Received: 10 July 2021

Accepted: 19 August 2021

Published: 25 August 2021

Publisher's Note: MDPI stays neutral with regard to jurisdictional claims in published maps and institutional affiliations.

Copyright: (c) 2021 by the authors. Licensee MDPI, Basel, Switzerland. This article is an open access article distributed under the terms and conditions of the Creative Commons Attribution (CC BY) license (https:/ / creativecommons.org/licenses/by/ $4.0 /)$.

\begin{abstract}
Highly appreciated concert halls have their own acoustic signature. These signatures may not often be consciously appraised by general audiences, but they have a significant impact on the appreciation of the hall. Previous research indicates that two of the most important defining elements of a hall's acoustic signature are (i) the reflection sequence and relative reflection levels at the listener position and (ii) the perceptibility of the reflections based on perception thresholds. Early research from Sir Harold Marshall identified the importance of unmasked early reflections to enhance a concert hall's acoustic signature. The authors see an opportunity to extend the existing research by further examining the sequence of unmasked reflections. By analysing the cross-sections of three concert halls, this manuscript quantifies potential links between a hall's architectural form, the resultant skeletal reflections, and the properties of its acoustic signature. While doing so, the manuscript identifies potential masking reflections through visual and analytical assessment of a hall's skeletal reflections. It is hypothesized that the "rhythm" of the reflection sequence could hold key insights into the hall's "personality" and acoustic signature. If so, this could present new design tools and considerations for new concert halls and the diagnosis of underperformance in existing halls.
\end{abstract}

Keywords: concert hall acoustics; lateral reflections; shoebox typology; spatial impression; perception thresholds; skeletal reflections; reflection sequence; perception thresholds

\section{Introduction}

Sir Harold Marshall defined Presence as "a dimension in which cultural phenomena and cultural events become tangible and have an impact on our senses and our bodies" [1]. How to achieve Presence in a space is a cross-disciplinary mission that involves the input of experts in several fields, acoustics among them. The concept of Presence is similarly described by Salter and Blesser, with the definition of Aural Spaces as places that have an impact on the emotions or the behaviours of the listeners [2]. Concert halls are spaces where thousands of people gather to share one-off experiences each evening and where the concepts of Presence and Aural Spaces become particularly relevant.

Every space has, at least, one purpose which should be engineered by the acoustic architect through a detailed understanding of the nuts and bolts of acoustics [2]. Spaces such as control rooms in recording studios are meant to be acoustically neutral, providing an exceptionally linear acoustic response that avoids any tone colouration between the monitors and the sound engineer. Concert halls, on the other hand, are meant to enhance the sound from the orchestra-nobody would enjoy listening to an orchestra in an anechoic chamber. Concert halls are an extension of the orchestra, with their own character, and like any other musical instrument, should be designed to be rich and unique. High-end violins, 
for example, are not appraised by their neutral and linear sound, but by their unique sound signature. Indeed, highly appreciated halls such as the Große Musikvereinssaal have a strong and unique sound, also described as a character or acoustic signature that has a significant impact on the appreciation of the hall by an audience.

Concert halls are collective instruments played by the conductor, by the orchestra as an ensemble, and by each musician independently. The best orchestras grasp the hall's character and integrate it as part of the musical expression. Needless to say, the acoustics of a concert hall, along with adding character to the sound, should provide favourable acoustic conditions for the orchestra and the learning curve should be gentle so that visiting orchestras can adapt to its acoustics quickly within a short seating call or warm-up rehearsal.

\section{Research Purpose}

The authors of this manuscript believe that the foundational concept of reflection sequence and its potential to enhance the acoustic signature of a concert hall has not been explored in enough detail as of yet. With this work, the authors aim to provide further insight into the potential relationship between the reflection sequence and the acoustic signature of a concert hall. The manuscript is structured as follows:

- Literature review;

- Acoustic signature;

- Reflection sequence;

- Perception thresholds;

- Skeletal Analysis of three shoebox concert halls;

- Potential masking diagram;

- Design features to potentially enhance the acoustic signature of a concert hall;

- Conclusions.

\section{Literature Review}

Four concepts are consistently used in this manuscript: acoustic signature, skeletal reflection, reflection sequence, and perception thresholds. Given that the three concepts are closely related, it is worth defining them first.

- Acoustic signature: the distinctive acoustic properties of an aural object;

- Skeletal reflections: discrete early reflection provided by major architectural elements;

- Reflection sequence: the temporal order and relative level of a set of discrete sound reflections;

- Perception threshold: the weakest sound stimulus that a human can sense.

The following paragraphs provide a brief historical reference and explain their relevance to the design of concert halls

\subsection{Acoustic Signature}

Humans possess an inherent spatial ability to understand their surroundings by how passive objects modify the acoustics of a space. The frequency content and level of background noises as well as the delays of sounds bouncing off passive objects creates an aural image to a listener. Therefore, to some extent, we can "see" with our ears thanks to our ability to decode spatial attributes using acoustic cues [2].

Shaping these passive objects-that is, the walls, ceilings, and architectural elements of concert halls-is a relatively young science. One of the major advances on the field was the finding of the effect of lateral reflections in 1952, when Meyer identified the apparent extension of a sound source with the presence of a sound reflection [3,4].

In the late 1960s, Marshall and Barron advocated that perceptible early lateral reflections were significant in improving Spatial Impression (SI) [5,6]. Marshall concluded that a sequence of skeletal reflections that are perceptible and unmasked could enhance the room response, providing the room with a "premium quality of acoustical experience" [7]. 
This statement is essential to understand the purpose of this work. While most of the standard acoustic parameters are based on energy integrals, the concept of unmasked reflection sequences provides an innovative approach to the design of concert halls to be used alongside the rest of the acoustic parameters.

In the 1970s, Wettschurek's research on the unmasking of reflections related to the loudness levels signalled a connection between SI and Loudness [8]. This research was followed up by Kahle et al. in 2017, linking the musical dynamic of a hall to the unique reflection sequence at a particular listening position as a reason why concert halls "wake up" differently [9]. A concert hall that "wakes up" as the dynamic increases could be interpreted as a concert hall that reveals its acoustic signature as its sequence of early reflections becomes unmasked as the overall reflection level increases.

Through a set of listening tests in 2011, the Aalto University team found that listeners could recognize a concert hall through its early sound, which is primarily composed of a sequence of early reflections created by the room's shape [10]. This reveals the strong connection between the sequence of early reflections and the recognizability of a concert hall.

Therefore, designing concert halls with a strong acoustic signature could be a strategy to create spaces that left an aural memory on the audience. Indeed, the mere-repeatedexposure effect describes that an individual exposed to familiar and new stimulus objects shows a preference for the familiar object. This could be one of the reasons why the Große Musikvereinssaal has become such an archetypical hall or why Funkhaus Studio 1, with its strong character, has become iconic for classical recordings.

From the literature, two elements with relevant influence on the signature of a concert hall are:

(i) The reflection sequence and relative reflection levels at the listener position.

(ii) The perceptibility of the reflections relative to the perception thresholds.

\subsection{Reflection Sequence}

For a particular listening position, a series of discrete early reflections are provided by the hall's architectural shape. These principal discrete reflections were identified as skeletal reflections (SR) by Marshall [5]. Based on a complex relationship between the arrival times, directions, and levels, certain reflections fall below or above the perception thresholds and are considered as masked or unmasked, respectively.

In 1981, Barron and Marshall attested that sound reflection levels add incoherently for SI-in short, the temporal order of reflections from different directions was deemed of little importance for SI $[3,11]$. As an objective criterion to measure SI, Barron developed the Lateral Energy Fraction (LF), which has been proven to correlate highly with subjective listener preferences. Probably due to the success of the LF criteria and other acoustic parameters, further design techniques related to the sequence of unmasked reflections have not been explored yet even though the applications of both concepts are complementary.

The acoustic parameters included in the ISO 3382-1:2009 "Acoustics Measurement of room acoustic parameters-Part 1: Performance spaces" provide a rich framework to interpret the acoustics of a concert hall. However, as suggested by Bradley, further research has to be done to fully understand missing elements such as the preferred design criteria or the most relevant range of frequencies for each parameter [12]. From this set of parameters, it is not clear which would allow distinguishing between "good" and "excellent" acoustics [10] or what makes a hall recognizable from other halls [13].

Furthermore, despite the Reverberation Time (RT), which is largely constant through a room, many other parameters are location-dependent, making it difficult to describe a room by a single number. For example, Clarity values have been proven to vary beyond the standard uncertainty even between two adjacent seats [14].

The early reflections are a sonic representation of the hall's architectural shape. Halls with a simple shape such as the Große Musikvereinssaal create a "simple" reflection sequence, while halls with a complex architecture generally provide a greater quantity 
of early reflections, creating a more complex acoustic signature. Halls including large amounts of acoustic diffusion or visual noise will gravitate towards a blurred or less obvious acoustic signature given that the early reflections are highly weakened, likely below the perception threshold.

Halls should be shaped to provide the best acoustic conditions for their intended use. Certain concert halls would benefit from a stronger acoustic signature to enhance the aural experiences, whereas other halls such as black box-type halls intended for amplified sound will benefit from more neutral acoustics.

\subsection{Perception Thresholds}

The perception of sound reflections in a concert hall does not only correspond to a binary audible/inaudible criterion but to a gradient of perceptibility with three main thresholds [15]:

(i) Detection threshold below which sound reflections are inaudible. In this work, the perception threshold term is used to reference this threshold.

(ii) Image-shift threshold above which reflections are audible but contribute to some spatial effect such as image-shift or localization blur.

(iii) Echo-threshold above which two separate auditory events are audible.

Acoustic perception thresholds were first investigated by Seraphim using speech signals for several source and reflection directions [16]. These are the perception thresholds that were used in the well-known 1967 note to the editors by Marshall, "A note on the importance of room cross-section in concert halls" [5].

A year later, Marshall published a second letter to the editors, "Levels of Reflection Masking in Concert Halls" after Schubert's research on the audibility of musical reflections in a concert hall $[17,18]$. This included Schubert's thresholds for a reflection at $\alpha=30^{\circ}$ using a choral motif, not a significant change compared to his previous paper but just a more appropriate use of detection thresholds. Schubert's data indicated that Seraphim's thresholds were unlikely to be applicable to the case of a concert hall, since the musical masking is, in any case, sustained much more than the masking of speech. This is because the listener perception is generally less sensitive to reflections if the sound signal is music instead of speech. Moreover, the reverberation in a concert hall renders the detection of a sound reflection even more difficult. Schubert also showed that the masking threshold level is approximately $10 \mathrm{~dB}$ lower for a lateral reflection normal to the direct sound than it is for a reflection having approximately the same direction as the direct sound $[17,18]$.

In 1970, Barron published "The Subjective Effects of First Reflections in Concert HallsThe Need for Lateral Reflections" [6]. This paper tested the threshold for a single side reflection at $\alpha=40^{\circ}$ with a Mozart motif at a mean level of $81 \mathrm{~dB}$. The results of this test are well known to acousticians and are often referenced in the literature.

Twenty-two years later, Olive and Toole continued the research on thresholds for audibility and image shift. Their research showed that the more reverberant the environment is, the higher the audibility threshold becomes [15,19]. From an acoustic point of view, the consequence of this finding is that if lateral reflections are to be perceived, the reflections should be strong and well above the threshold of audibility. Even surfaces with low levels of scattering or residual acoustic absorption could drag these reflections below the audibility threshold in a reverberant field, making them imperceptible.

As part of their work, Olive and Toole prepared a complete comparison of audibility thresholds, which can be found in [19]. For reference, Schubert's "Handel Concerto Grosso" in that comparison was the threshold used in Marshall's second note and in this manuscript. Schubert's work on perception thresholds is even cited in relevant books such as Kuttruff's Room Acoustics [20].

Strong lateral reflections have been shown to enhance musical dynamics and the dynamic responsiveness in concert halls [21,22]. The literature also shows that in most cases, image-shift thresholds are significantly higher than detection thresholds. This means that reflections must be substantially louder than just detectable to mislead localization [15]. 
Image shift produced by early reflections is likely due to a combination of a strong reflection arriving after a weakened direct sound and/or low energetic early reflections. In the authors' previous experience, cases of image shift are often found on the voice signal of opera singers, likely accentuated by the lack of stage enclosure to fill with the gap between the direct sound and the first hall reflection.

While scattered reflections below the audibility threshold have the potential to increase acoustic parameters values such as LF or Clarity, Lokki et al. indicated that sound reflections from scattering surfaces will result in Temporal Envelope Distorting (TED) reflections, making it difficult for these reflections to be fused with the direct sound [10].

\subsubsection{Overall Listening Levels and Angle of Arrival}

The perception thresholds also depend on the overall listening levels. This was first investigated by Wettschurek in 1976 [8]. Forty years after the original publication, Green et al. revived the topic and demonstrated how reflections from different directions and arrival times are masked or unmasked at different overall listening levels [22].

From Wettschurek's work, the main conclusion of interest for this manuscript is that the relative perception threshold for lateral and frontal reflections is dependent on the overall listening levels. The perception threshold for a lateral reflection at pianississimo is up to $8 \mathrm{~dB}$ higher than for a forte. Reflections that are felt under the perception threshold at lower listening levels would be perceived during crescendos. Green et al. refer to this effect as dynamic responsiveness or how a concert hall "wakes up" [22].

\subsubsection{Note on Perception Thresholds}

As shown above, several authors have shed light on perception thresholds, greatly improving the general knowledge under different listening conditions and sources. However, the reader should note the these are highly case-dependent, and this effect is magnified when considering the circumstances and listening experience of each member of an audience.

Similar to the precautions provided by Barron in 1971 [6], the perception thresholds should be interpreted as a baseline for the design of concert halls. Despite their relative "objectiveness" provided in the literature and this manuscript, the reader should be aware that the thresholds are highly case-dependent and should be understood as such.

\section{Skeletal Reflections Analysis}

\subsection{Introduction}

The Skeletal Reflections Analysis is a visually descriptive medium to evaluate and compare halls. It also enables the identification of potential relationships between a reflection sequence and the acoustic signature of a concert hall.

This analysis is generally applied to the cross-section of shoebox concert halls. For further typologies, a 3D analysis would be better suited.

This method was first introduced by Marshall [5]. The analysis was applied to the wall boundaries of two theoretical hall shapes to shed light on the importance for lateral reflections to arrive earlier than ceiling reflections in order to avoid masking.

While the original procedure did not include sound reflectors or galleries, this work includes the architectural elements, which can provide strong Temporal Envelope Preserving (TEP) reflections [10]. These elements are mostly flat or slightly curved and large enough to reflect the $125 \mathrm{~Hz}$ frequency band, which roughly corresponds to surfaces larger than $2.7 \mathrm{~m}$. For corner reflections, the total surface considers the vertical and horizontal components.

The power of this analysis lies in its simplicity, which can be executed using the backof-an-envelope approach and still provide great insights, which can be used for decision making at any stage of a design.

For the set of concert halls included in this work, the SRs are manually found in the cross-section. The automatization of the procedure by the use of the Image-Source method is an option; however, a critical selection of reflections should be made. The inclusion of non-relevant reflections would complexify the analysis. 


\subsection{Methodology}

The Skeletal Reflections Analysis in this manuscript is consistent with the procedure followed by Marshall. The reader should refer to the original paper for an in-detail description of the procedure [5]. In short, the procedure as applied in this work is the following:

- A simplified cross-section of a shoebox concert hall is used;

- A source position $S$ on stage is assumed. The receiver $R$ is considered at $18.3 \mathrm{~m} \mathrm{(60} \mathrm{ft)}$ from the stage located $1 \mathrm{~m}$ off-axis from the centre line of the hall;

- The cross-section represents the concert hall in the middle point between the stage and the source position;

- The cross-section is then placed on the same plane as the source, as shown in Figure 1. This assumes that all reflecting surfaces in the plane with the source are angled such that they provide a reflection to the receiver. The relocation of the cross-section may be counterintuitive, but it is consistent with the original procedure. It is the subject of discussion and may be modified in future analysis;

- The skeletal reflections points are identified and represented as numbered black dots. The image sources are calculated and identified as grey numbered dots;

- The levels of the reflections are based on the path length and the effect of grazing incidence and scattering surfaces. The effect of grazing incidence to a seat in the centre of the audience is accounted for as

- $-15 \mathrm{~dB}$ for a flat floor configuration [23],

$\circ \quad-10 \mathrm{~dB}$ for a gentle audience rake $\left(5-6^{\circ}\right)\left({ }^{*}\right)$, and

- $\quad-5 \mathrm{~dB}$ for a steeper audience rake $\left(10-11^{\circ}\right)\left({ }^{*}\right)$;

- The effect of scattering surfaces is accounted as $-5 \mathrm{~dB}$ per bounce [24];

$(*)$ author's assumptions.

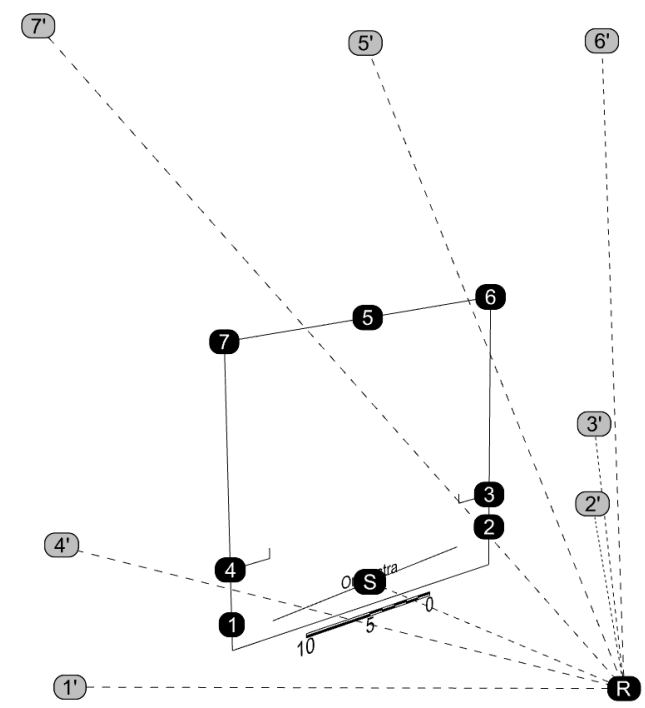

Figure 1. Skeletal reflections procedure, graphical explanation. The source position is named $\mathrm{S}$, and the receiver is $\mathrm{R}$. The numbers in black dots indicate the sound reflection position, grey dots indicate image sources positions. The procedure and graphs were produced using a custom script in Grasshopper for Rhino3d.

- Data from Schubert are used to draw the reflections' absolute threshold and probable threshold for useful contribution [18];

- To facilitate the reading of the echograms, the reflections have been numbered from the bottom up. Zero (0) corresponds to the direct sound. One (1) and two (2) represent the two grazing lateral reflections. The rest of the reflections are case-dependent.

In reality, concert halls have numerous reflections, and an orchestra with multiple directivity patterns can hardly be assumed to be represented by a single point source as in 
the Skeletal Analysis in Marshall's procedure. However, the simplified echogram based on SRs presented by Marshall and explored in this manuscript serves as a preliminary tool at the early phases of the design. During the design phase, multiple sources and seat locations with varying overall levels should be compared.

\subsection{Case Studies}

A set of concert halls with common characteristics has been selected for comparing SRs. The selection criteria are:

- Shoebox typology;

- Similar capacity;

- The halls should have proven successful acoustics.

The list of concert halls along with an overview of their capacity, dimension, and pictures are shown in Table 1 and Figure 2.

Table 1. Data for selected concert halls.

\begin{tabular}{|c|c|c|c|c|c|c|}
\hline Concert Hall & Code & Capacity (N) & $\begin{array}{c}\text { Volume }(\mathrm{V}) \\
{\left[\mathrm{m}^{3}\right]}\end{array}$ & $\mathrm{V} / \mathrm{N}\left[\mathrm{m}^{3} / \mathrm{seat}\right]$ & $\mathrm{RT}_{500-1000, \mathrm{occ}}[\mathrm{s}]$ & $\begin{array}{c}\text { Floor Rake at } \\
\text { Stalls }\end{array}$ \\
\hline $\begin{array}{c}\text { Große } \\
\text { Musikvereinssaal }\end{array}$ & GMV & 1680 & 15,000 & 8.9 & 2.0 & $0^{\circ}$ \\
\hline Perth Concert Hall & $\mathrm{PCH}$ & 1729 & 15,650 & 9.0 & 2.1 & $10-11^{\circ}$ \\
\hline $\begin{array}{c}\text { Stavanger } \\
\text { Konserthuset [25] }\end{array}$ & SK & 1500 & 22,168 & 14.8 & 2.2 & $5-6^{\circ}[26]$ \\
\hline
\end{tabular}

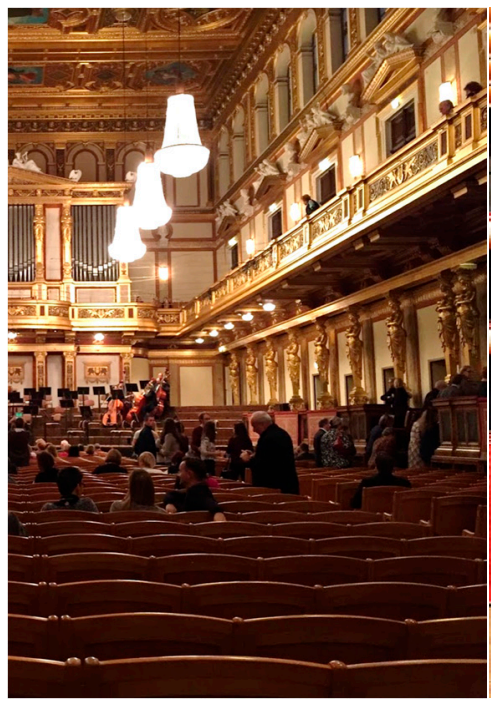

(a) GMV

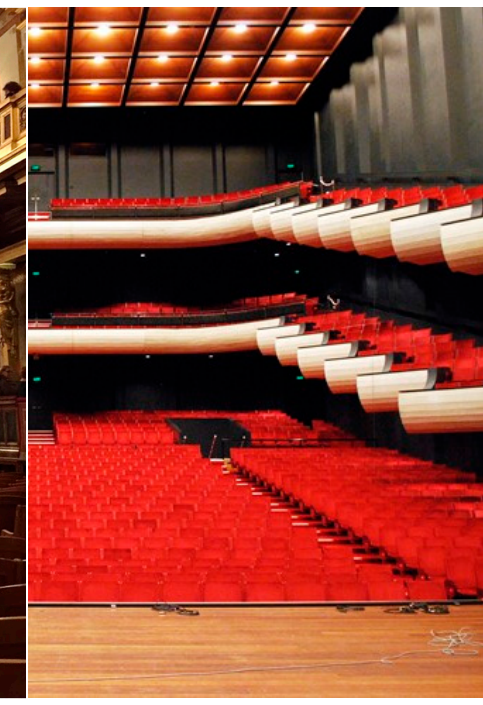

(b) $\mathrm{PCH}$

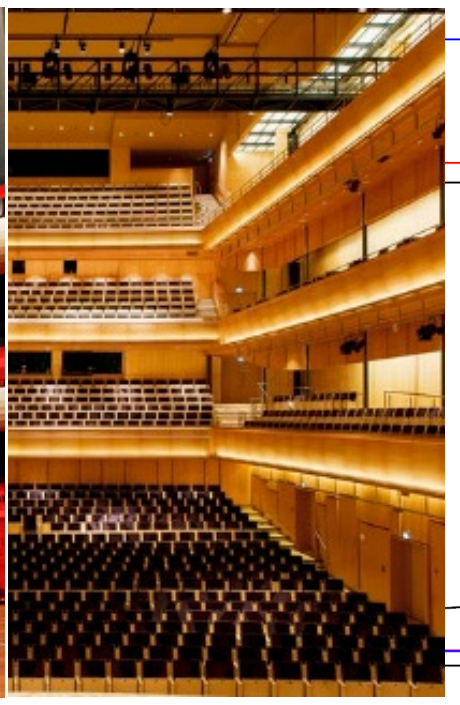

(c) SK

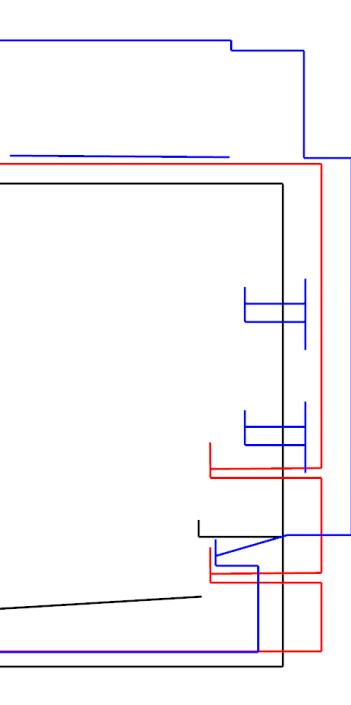

(d) Comparison

Figure 2. (a) Große Musikvereinssaal (photo: J.O. García); (b) Perth Concert Hall (photo: Marshall Day Acoustics); (c) Stavanger Konserthuset (photo: https://sso.no/en/seating-plan-fartein-valen/ accessed on 24 August 2021); (d) Comparison of concert hall's cross-section: (Black) Große Musikvereinssaal, (Red) Perth Concert Hall, (Blue) Stavanger Konserthuset [25].

\subsection{Analysis}

The Skeletal Analysis is presented in the form of an echogram. The vertical lines indicate the arrival of an SR, which is the height of the line related to the relative level to the theoretical unobstructed direct sound. The numbers above each vertical line represent the location where the reflection happens, indicated in a short section adjacent to the echogram. Two perception thresholds are shown in the SR echogram in Figure 3 (dashed line), absolute threshold of perceptibility after Schubert (solid line), probable threshold for 
useful contribution. The absolute arrival time and the Initial Time Delay Gap (ITDG) are shown in the horizontal axis of the echogram.
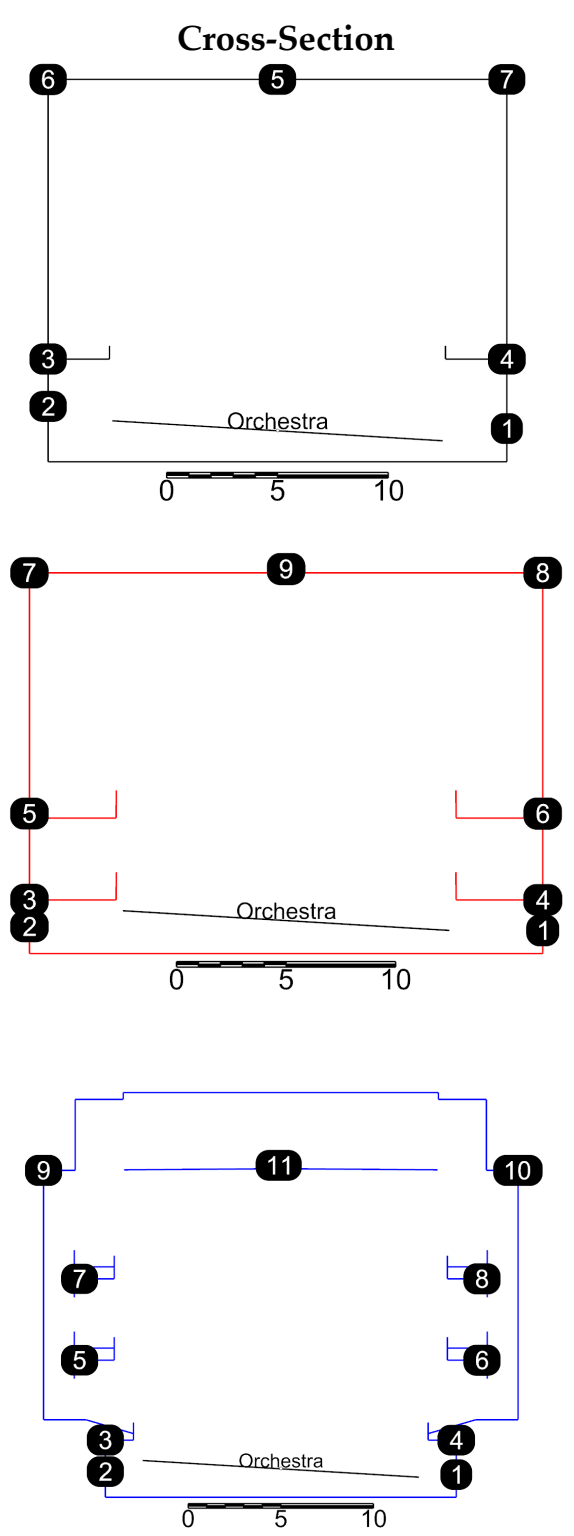

Skeletal Reflections Echogram

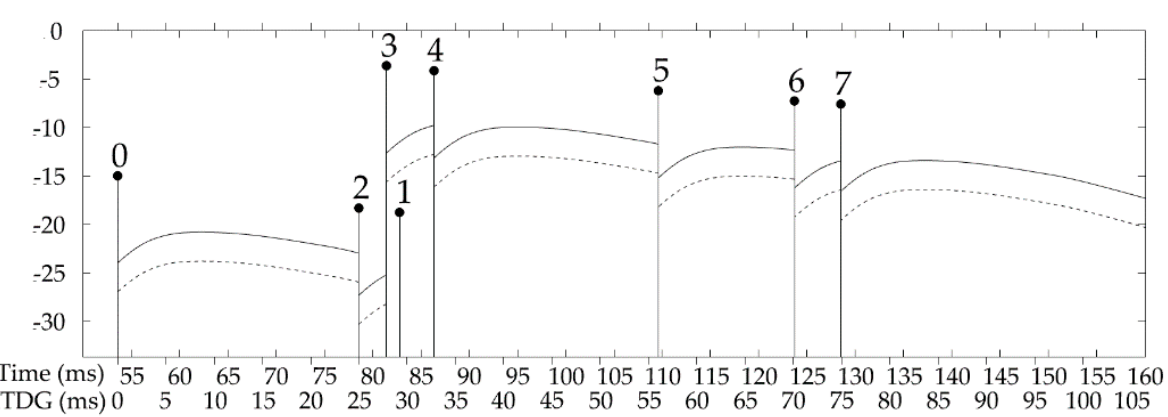

(a) Große Musikvereinssaal

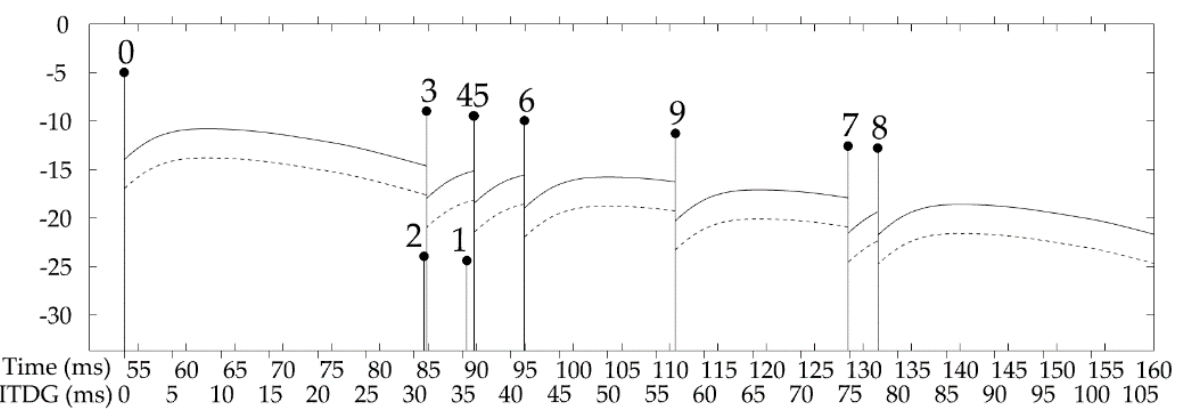

(b) Perth Concert Hall

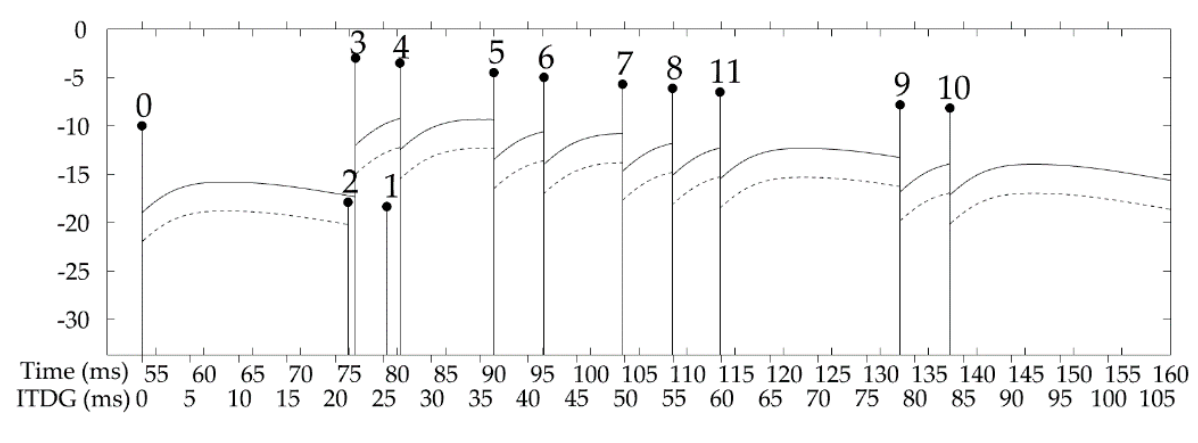

(c) Stavanger Konserthuset

Figure 3. Skeletal Reflections Analysis for three concert halls: (a) Große Musikvereinssaal, (b) Perth Concert Hall, (c) Stavanger Konserthuset. Time indicates the absolute time of arrival, and Initial Time Delay Gap (ITDG) is the arrival time after the direct sound. The dashed line indicates the absolute threshold of perceptibility after Schubert. The solid line is the probable threshold for useful contribution.

The reader should note that reflections from the stage enclosure fill the time gap between the direct sound and the first lateral but are not shown in this analysis. The stage enclosure reflections, due to their direction and the arrival time, are generally masked by the direct sound but contribute to filling in the gap between the direct sound and the first halls reflection.

When analysing the SRs in Figure 3, the reader should note that as discussed above, the perception thresholds for lateral reflections are lower than from any other direction. Therefore, in reality, if two reflections arrive simultaneously from two different directions, it is likely that the more lateral (perpendicular to the ear) reflection will predominate and 
mask the other. Relative reflection levels in the analysis below do not compensate for direction nor overall listening levels.

Regarding the attenuation of the direct sound, halls with a flat floor will be the most affected by audience attenuation. In the original analysis, Marshall used a $15 \mathrm{~dB}$ attenuation in excess of the inverse square law based on data from Schulz and Watters [23]. The steeper audience rakes are the less affected ones. The following convention has been followed: flat floor $-15 \mathrm{~dB}(\mathrm{GMV})$; gentle audience rake $-10 \mathrm{~dB}(\mathrm{SK})$; pronounced audience rake $-5 \mathrm{~dB}(\mathrm{PCH})$.

\subsection{Results}

The analysis of the cross-section is divided into three main groups: Lower room, sidewalls, and ceiling. The rhythm and density of SRs are not related to the quality of the acoustic signature. The presence of a recognizable acoustic signature is important for the subjective quality of a concert hall. However, the properties of this signature can and should be different, depending on the hall's musical and architectural purpose.

\subsubsection{Lower Room}

Reading the echograms from left to right will tell us which hall provides the quickest early reflection of the three halls, which is related to ITDG and Acoustic Intimacy.

In halls with flat floor or gentle audience rake, very early overhead reflections are critical to provide reflections that enhance the direct sound which is very much obstructed by the audience. In this case, SK due to its narrow parterre and the first balcony soffit (reflections 3-4) provides the earliest lateral overhead reflections.

In halls with full-width stalls of $23-25 \mathrm{~m}$, the first lateral reflection will only arrive at 30-40 ms after the direct sound, as is the case of PCH. Even though the energy from a first early reflection arriving at that time contributes to enhancing Clarity and Early Energy, other important criteria such as Acoustic Intimacy would benefit from the shortest ITDG possible.

In the set of studied concert halls, $\mathrm{PCH}$, which has a wider parterre also has a steeper audience rake. This allows for an unobstructed direct sound that compensates for the "late" first early reflection. In addition to ITDG, Lokki et al. suggest the spectrum of the sound reflections is important to enhance intimacy; low and high-frequencies enhance it more than mid-frequencies [27]. Therefore, the use of large or fine-scale scattering applied to the sidewalls could reduce the subjective impression of intimacy. In the three halls in this manuscript, the use of fine-scale scattering is residual. Even in the GMV, which is believed to be highly diffused, Marshall pointed out that "inspection shows that there is far more plane surface than one would think" [28].

Generally, finding strategies to physically narrow the room will improve acoustic and visual intimacy by creating earlier first lateral reflections, resulting in the audience feeling closer to the stage. This design approach was also employed for the Philarmonie de Paris. In this case, the balconies and clouds were narrowed to create an acoustic and visual intimate room within a larger reverberant volume [29-32].

\subsubsection{Sidewalls}

There are two clear design approaches in this set of concert halls. First, GMV and $\mathrm{PCH}$ were designed to provide quick second-order overhead lateral reflections from relatively low balcony undersides, which arrive virtually simultaneously with the sidewall reflections. This results in enhancing the direct sound, increasing Apparent Source Width, and creating envelopment. Above the side balconies, the relatively flat walls go all the way up to the ceiling. These large upper wall surfaces are providing a breath, or reflection-free time window between the first reflections and the ceiling reflection. The Skeletal Analysis of GMV and PCH shows a clear separation between the direct sound, first lateral reflections, ceiling reflection, and late-ish early reflections. This distinction between the sound fields 
could align with Lokki's impressions on GMV, indicating that this distinction would preserve articulation and reduce masking the onset of notes [27].

$\mathrm{PCH}$ includes two overhead reflections from the undersides of the second balcony (5-6). These reflections arrive barely 5-10 ms after the first balcony reflections (3-4), increasing the risk of temporal masking.

In contrast to the low balconies and flat empty upper walls of GMV, SK exhibits a rational balcony height distribution and a denser short section. This feature is meant to deliver a great amount of early energy to the audience to enhance the early lateral sound, providing high clarity in a larger volume-SK is $7000 \mathrm{~m}^{3}$ larger than GMV and $\mathrm{PCH}$.

The rhythm of reflections shown in the echograms is immediately obvious. Halls like SK show a denser echogram between $20 \mathrm{~ms}$ and $60 \mathrm{~ms}$ after the direct sound. This is informed by the number of early reflections provided by the balconies soffits compared to GMV. Based on the Skeletal Analysis, the presence of multiple reflections from side balconies would increase the chances of masking the ceiling reflection, which is harder to perceive due to a higher perception threshold for zenith reflections as shown by Wettschurek [8].

\subsubsection{Ceiling}

A ceiling reflection has a great potential to "open" the room, i.e., to enhance the room perception and the feeling of being in a large volume. However, if this reflection arrives too late, or if due to limited or no lateral reflections, the preceding reflection-free period would be too long, it could make the ceiling reflection be perceived as an echo. In the case of an excessively late ceiling reflection for major reasons, providing a strong reflection sequence beforehand could help to reduce the risk of echo by renovating the precedence effect.

The risk of echo perception motivates the use of highly diffusive ceilings that do avoid echoes but also misses all the above-mentioned aural benefits. Instead of designing to avoid risks, the ceiling reflections can be fine-tuned by:

- Limiting the ceiling height to $18 \mathrm{~m}$, a rule-of-thumb limit for large shoeboxes;

- Creating enough lateral reflections;

- Accounting for the higher perception threshold for zenith reflections.

The three halls analysed show a similar approach to ceiling reflections. $\mathrm{PCH}$ and SK include some sort of diffusiveness to the ceiling when compared to GMV- $\mathrm{PCH}$ a coffered ceiling and SK convex reflector panels-but all the halls allow for relatively strong ceiling reflections, which might be important for their success. GMV and $\mathrm{PCH}$ provide a considerable reflection-free time before the ceiling reflection, GMV almost $20 \mathrm{~ms}, \mathrm{PCH}$ $15 \mathrm{~ms}$. The reflection-free time provided by SK is variable between $5-15 \mathrm{~ms}$, depending on the movable ceiling position. This reflection-free period was first mentioned by Marshall, and given the quality of these concert halls, it is an acoustic feature that should be at least considered for the development of a new hall to avoid potential masking.

\section{Potential Masking Diagram}

When analysing the cross-section of a concert hall, one of the main goals is to identify which reflections may be masked. Once identified, it is up to the acoustician to modify the shape of the room to avoid potential masking. Of interest for this work is the creation of aural cues that could provide the room with an acoustic signature.

Complementary to the Skeletal Analysis, the Potential Masking diagram is proposed by the authors as a technique to visualize which architectural elements provide simultaneous sound reflections.

Figure 4 shows the Potential Masking diagram applied to the cross-section of the three concert halls. Each cross-section incorporates a series of circles centred at the source position. Each circle corresponds to the arrival of the first reflection after the direct sound from a source on the stage edge to a receiver at $18.3 \mathrm{~m}$-the same as used for the Skeletal Masking Analysis. The analysis is straightforward: architectural elements provide reflections to the audience, which share a curve that could lead to masking sound reflections. 


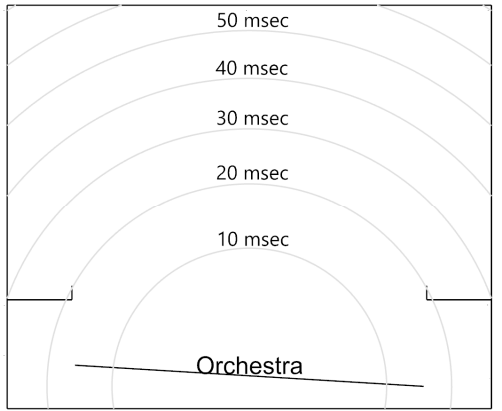

(a) GMV

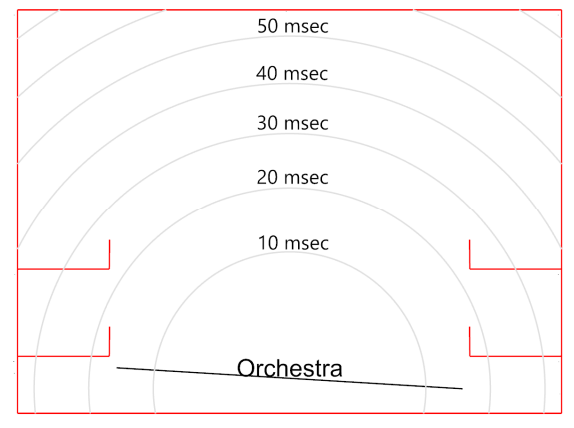

(b) $\mathrm{PCH}$

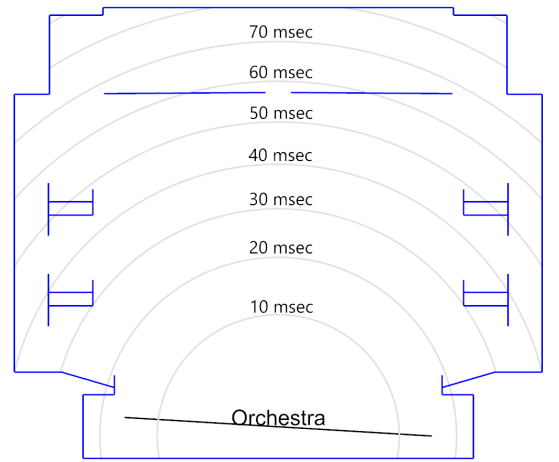

(c) SK

Figure 4. Potential Masking diagram for three concert halls: (Black) Große Musikvereinssaal, (Red) Perth Concert Hall, (Blue) Stavanger Konserthuset.

From Figure 4, the influence of the parterre width can be seen -the narrower parterre (SK) provides the first lateral reflections around 20-25 ms-whereas in the wider ones, the first lateral reflections only reach the receiver around 30-35 ms.

It is also common for various halls to have a balcony providing strong second-order reflections that is on the same circle as the ceiling. This could lead to masking the ceiling reflection (given that the threshold for a lateral reflection is lower than for the ceiling), which could lead to a room that "opens" less easily. The use of curved surfaces, as is the case of the vertical soffits in SK, mitigates the strength of the lateral reflections that could mask the ceiling reflection. Note these are potential effects that could be important cues for the acoustician when designing or fine-tuning a concert hall.

As a rule of thumb, avoiding architectural elements that create SRs being located on the same arc may increase the chances for the reflections to be unmasked and therefore meaningful for the acoustic signature of the room.

\section{Conclusions}

\subsection{Potential Room Signature Enhancers}

From the Skeletal Reflections Analysis of three successful venues, a series of design techniques have emerged as potential enhancers of the concert hall acoustic signature based on the cross-section. These are summarised as follows:

- Avoiding bunched SRs;

- Providing a reflection-free period in the order of $10-15 \mathrm{~ms}$ before key SRs;

- Fine-tuning the energy of the SRs-the perception thresholds can be used as context to evaluate the sound energy;

- Creating a sequence of "strong" SR to reduce the risk of image shift and echoes.

The reader should note these features are hypotheses, and further research, including listening tests, is required.

\subsection{General}

Early research from Marshall identified the importance of unmasked early reflections. The authors have sought to further this research and address a perceived gap in the existing literature.

The authors consider the sequence of reflections a key feature of the hall geometry that has significant influence on the hall's acoustic signature. Through analysing the crosssection of three concert halls, this manuscript quantifies potential links between a hall's architectural form, the resultant SRs, and the properties of its acoustic signature.

While doing so, the manuscript identifies potential masking reflections through visual and analytical assessment of a hall's SRs. 
The "rhythm" (bunching and spaces) of the discrete reflection sequence could hold key insights into the hall's acoustic signature. If so, this could hold ramifications on the design of new concert halls and the diagnosis of underperformance in existing concert halls.

This work so far has focussed on theoretical investigations, and further research is required. The authors hope to continue this research and test the resultant hypotheses through a series of listening tests using 3D impulse responses.

Author Contributions: Conceptualization, J.Ó.G.G., O.W., E.v.d.B., J.S. and T.H.; methodology, J.Ó.G.G.; software, J.Ó.G.G.; validation, J.O.G.G., O.W., E.v.d.B., J.S. and T.H.; formal analysis, J.Ó.G.G.; investigation, J.Ó.G.G.; resources, J.Ó.G.G.; data curation, J.Ó.G.G.; writing-original draft preparation, J.O.G.G.; writing-review and editing, O.W., E.v.d.B., J.S., T.H. and L.K.; visualization, J.Ó.G.G.; supervision, J.Ó.G.G., O.W., E.v.d.B., J.S. and T.H.; project administration, J.Ó.G.G.; funding acquisition, J.Ó.G.G.; All authors have read and agreed to the published version of the manuscript.

Funding: This research was funded by Marshall Day Acoustics Ltd.

Acknowledgments: This research would not have been possible without the innovative research by Harold Marshall. His enthusiasm and scientific contribution to the development of concert halls is a source of inspiration. His guidance and exchanges during the development of this research are greatly valued.

Conflicts of Interest: The authors declare no conflict of interest.

\section{References}

1. Marshall, A.H. Acoustical dimensions for production of presence in music spaces. In Proceedings of the IOA Auditorium Acoustics, Hamburg, Germany, 4-6 October 2018.

2. Salter, L.R.; Blesser, B. Spaces Speak, Are You Listening? Experiencing Aural Architecture; MIT Press: Cambridge, MA, USA, 2009.

3. Marshall, A.H.; Barron, M. Spatial responsiveness in concert halls and the origins of spatial impression. Appl. Acoust. 2001, 62, 91-108. [CrossRef]

4. Richardson, E.G.; Meyer, E. Technical aspects of sound. Phys. Today 1963, 16, 82-84. [CrossRef]

5. Marshall, A.H. A note on the importance of room cross-section in concert halls. J. Sound Vib. 1967, 5, 100-112. [CrossRef]

6. Barron, M. The subjective effects of first reflections in concert halls-The need for lateral reflections. J. Sound Vib. 1971, 15, 475-494. [CrossRef]

7. Marshall, A.H. Acoustical determinants for the architectural design of concert halls. Arch. Sci. Rev. 1968, 11, 81-87. [CrossRef]

8. Wettschurek, R. Über die Abhängigkeit Raumakustischer Wahrnehmung von der Lautstärke. Ph.D. Thesis, Technical University of Berlin, Berlin, Germany, 1976.

9. Kahle, E.; Green, E.; Knauber, F.; Wulfrank, T.; Jurkiewicz, Y. How (and why) does every Concert Hall “wake up" differently? J. Acoust. Soc. Am. 2017, 141, 3599. [CrossRef]

10. Lokki, T.; Pätynen, J.; Tervo, S.; Siltanen, S.; Savioja, L. Engaging concert hall acoustics is made upof temporal envelope preserving reflections. J. Acoust. Soc. Am. 2011, 129, EL223-EL228. [CrossRef] [PubMed]

11. Barron, M. Basic design techniques to achieve lateral reflctions in concert halls. In Proceedings of the International Symposium on Room Acoustics, Amsterdam, The Netherlands, 15-17 September 2019.

12. Bradley, J.S. Review of objective room acoustics measures and future needs. Appl. Acoust. 2011, 72, 713-720. [CrossRef]

13. Haapaniemi, A.; Lokki, T. Identifying concert halls from source presence vs. room presence. J. Acoust. Soc. Am. 2014, 135, EL311-EL317. [CrossRef] [PubMed]

14. Witew, I.; Dietrich, P.; de Vries, D.; Vorländer, M. Uncertainty of room acoustic measurements-How many measurement positions are necessary to describe the conditions in auditoria? In Proceedings of the International Symposium on Room Acoustics, Melbourne, Australia, 29-31 August 2010.

15. Sheaffer, J. From Source to Brain: Modelling Sound Propagation and Localisation in Rooms. Ph.D. Thesis, University of Salford, Salford, UK, 2013.

16. Seraphim, H.P. Über die wahrnehmbarkeit mehrerer Ruckwurfe von Sprachschall. Acta Acust. United Acust. 1961, 11, 80-91.

17. Marshall, A.H. Levels of reflection masking in concert halls. J. Sound Vib. 1968, 7, 116-118. [CrossRef]

18. Schubert, P. Untersuchungen über die Wahrnehmbarkeit von Einzelrückwürfen bei Musik. Technische Mitteilung RFZ 1966, 3 , 124-127.

19. Olive, S.E.; Toole, F.E. The detection of reflections in typical rooms. J. Audio Eng. Soc. 1989, 539, 539-553.

20. Kuttruff, H. Room Acoustics; Applied Science Publishers: London, UK, 1979.

21. Pätynen, J.; Tervo, S.; Robinson, P.W.; Lokki, T. Concert halls with strong lateral reflections enhance musical dynamics. Proc. Natl. Acad. Sci. USA 2014, 111, 4409-4414. [CrossRef] [PubMed]

22. Green, E.; Kahle, E. Dynamic spatial responsiveness in concert halls. Acoustics 2019, 1, 549-560. [CrossRef]

23. Schulz, T.; Watters, B.C. Propagation of sound across audience seating. J. Acoust. Soc. Am. 1964, 36, 885-896. [CrossRef] 
24. Ryu, J.K.; Jeon, J.Y. Subjective and objective evaluations of a scattered sound field in a scale model opera house. J. Acoust. Soc. Am. 2008, 124, 1538-1549. [CrossRef]

25. Kahle, E.; Möller, H.; Ognedal, T. The New Concert Hall in Stavanger. In Proceedings of the Institute of Acoustics, Reading, UK, 10-11 April 2008.

26. Kahle, E.; Jurkiewicz, Y.; Katz, B.F. Stavanger concert hall, acoustic design and measurement results. In Proceedings of the Institute of Acoustics, Paris, France, 29-31 October 2015.

27. Lokki, T.; Pätynen, J.; Tervo, S.; Kuusinen, A.; Tahvanainen, H.; Haapaniemi, A. The secret of the Musikverein and other shoebox concert halls. In Proceedings of the Institute of Acoustics, Paris, France, 29-31 October 2015.

28. Marshall, A.H. On the architectural implications of "diffusing surfaces". In Proceedings of the IOA Auditorium Acoustics, Hamburg, Germany, 4-6 October 2018.

29. Marshall, A.H.; Day, C.W. The conceptual acoustic design for La Philharmonie de Paris, Grande Salle. In Proceedings of the Institute of Acoustics, Paris, France, 29-31 October 2015.

30. Barron, M.; Marshall, A.H. Spatial impression due to early lateral reflections in concert halls: The derivation of physical measure. J. Sound Vib. 1981, 77, 211-232. [CrossRef]

31. Kahle, E. Halls without qualities-Or the effect of acoustic diffusion. In Proceedings of the Institute of Acoustics: Auditorium Acoustics, Hamburg, Germany, 4-6 October 2018.

32. Kirkegaard, L.; Gulsrud, T. In search of a new paradigm: How do our parameters and measurement techniques constrain approaches to concert hall design? Acoust. Today 2011, 7, 7-14. [CrossRef] 